\title{
Identifying the Components of a Healthy Lifestyle with Emphasis on Adolescence: A Qualitative Study
}

\begin{abstract}
Background and Objective: The issue of health as an individual and social capital, considering its importance for the growth and prosperity of the individual and society, has long been considered by thinkers in various fields. The aim of this study was to identify the components of a healthy lifestyle with emphasis on adolescence.

Materials and Methods: This research was conducted with a qualitative approach and content analysis method. The study population consisted of valid scientific documents related to healthy lifestyle that 47 articles (35 Persian articles and 12 Latin articles) related to the year 2000 were selected as the sample using purposive sampling method. To conduct research through the study of scientific articles related to healthy lifestyle, first the basic concepts were extracted and assigned to subcategories and subcategories to the main categories. The research tool included note-taking slips. Data analysis method was performed based on contractual (inductive) qualitative content analysis and in three stages, basic concepts, subcategories and main categories were extracted manually.

Results: The results showed that healthy lifestyle categories include four main categories and 12 sub-categories including physical health (mobility, nutrition, proper sleep pattern, reduction of high-risk behaviors, health responsibility, accident prevention and Self-care). Mental health (stress management, self-fulfillment, positive thinking and mindfulness), social health (interpersonal relationships) and spiritual health (spiritual growth). The number of initial concepts was 62 .

Conclusion: It is hoped that by teaching these subcategories to adolescents, a healthy lifestyle can be created for them and thus help improve adolescents' health. Keywords: life style, Qualitative Study, adolescence Paper Type: Research Article.
\end{abstract}

Citation (Vancouver): Khosravi M, Saemi H, Hosseinaei A, Bayani A. Identifying the Components of a Healthy Lifestyle with Emphasis on Adolescence: A Qualitative Study. Iran J Health Educ Health Promot. Spring 2021;9(1): 80-93. [Persian]

- Citation (APA): Khosravi M., Saemi H., Hosseinaei A., Bayani A. Identifying the Components of a Healthy Lifestyle with Emphasis on Adolescence: A Qualitative Study. Iranian Journal of Health Education \& Health Promotion., 9(1), 80-93 . [Persian]
Malihe Khosravi

PhD student of Curriculum studies, Psychology and education department, Azadshahr branch, Islamic Azad University, Azadshahr, Iran

Hassan Saemi

* Assistant Professor of Psychology department, Azadshahr branch, Islamic Azad University, Azadshahr, Iran. (corresponding author)

saemi_61@yahoo.com

Ali Hosseinaei

Assistant Professor of Psychology department, Azadshahr branch, Islamic Azad University, Azadshahr, Iran

Ali Asghar Bayani

Associate Professor of Psychology department, Azadshahr branch, Islamic Azad University, Azadshahr, Iran

Received: 2020/08/15

Accepted: 2021/01/31

Doi: 10.52547/ijhehp.9.1.80 


\section{شناسايى مؤلفه هاى سبك زندكى سلامتمحور با تأكيد بر دوره نوجوانى: يك مطالعه كيفى}

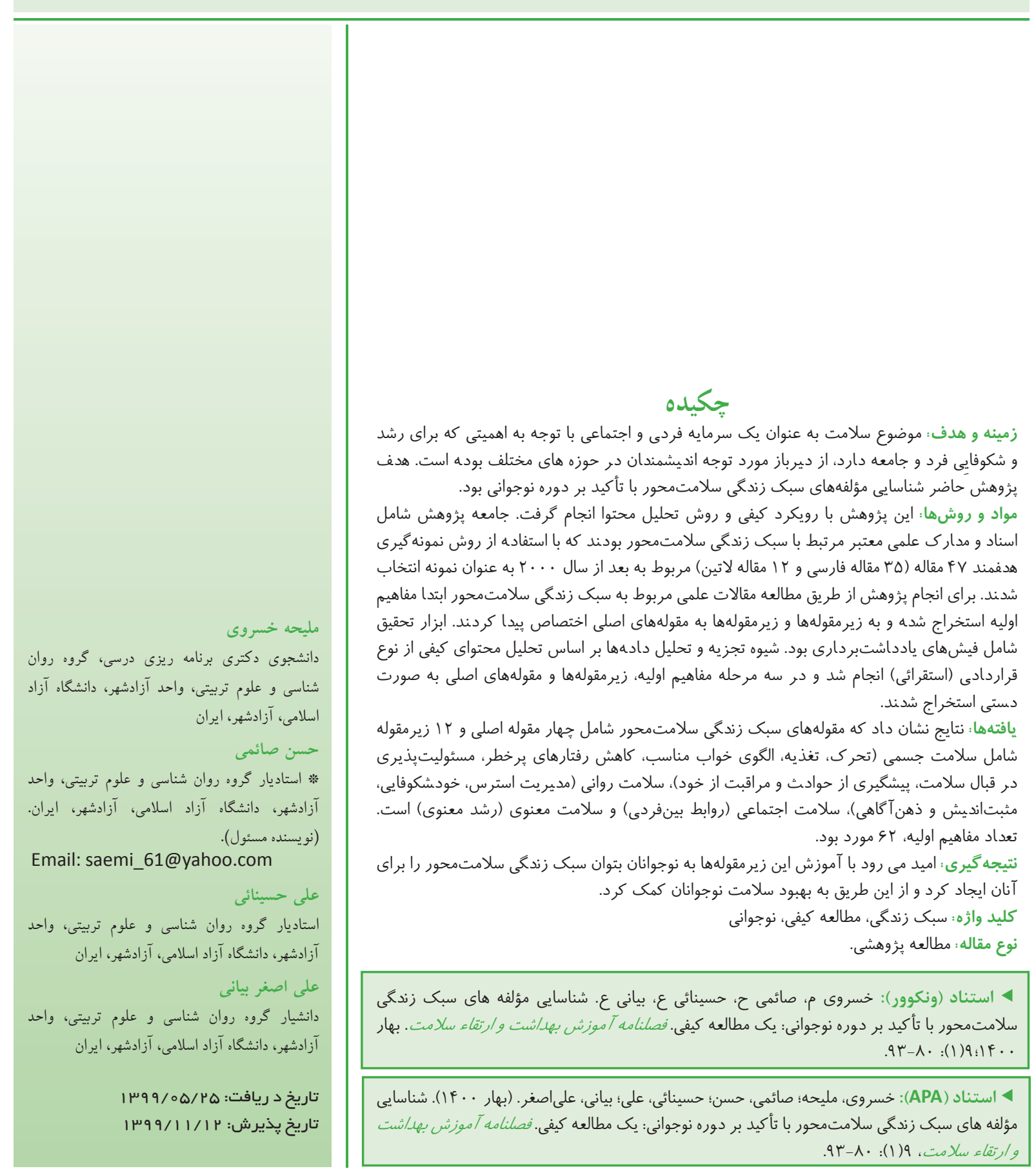


بنيادى در سلامت است. هامبور گ و همكاران بر آورد كردماند كه

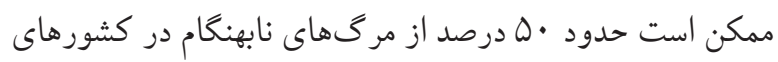

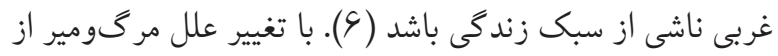

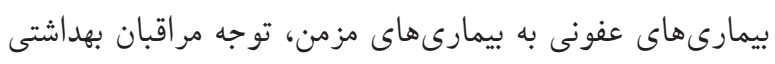

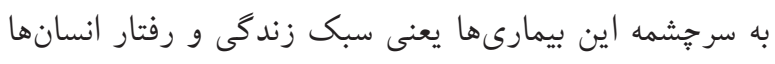
معطوف كثته است. عواملى مانند استعمال سيكار، الكوى تغذيه نامناسب، نداشتن فعاليت جسمانى، صدمه ديدن و ... از مهمتر ين الكين

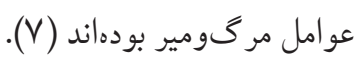

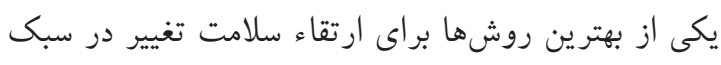
زندگى براى ارتقاء سلامت و سبك زندكى سلامت - محور باست.

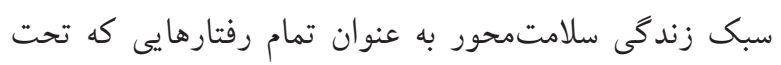

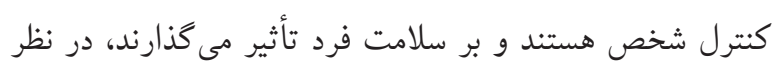

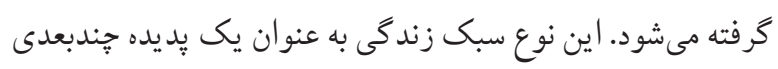

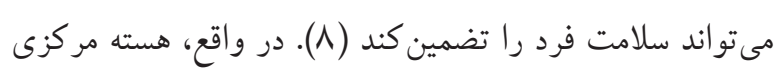

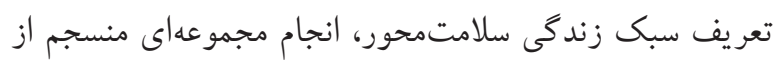
رفتارهاى مر بوط به بهداشت و سلامت است و شامل ابعاد متنوعى سلى

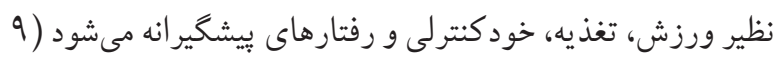

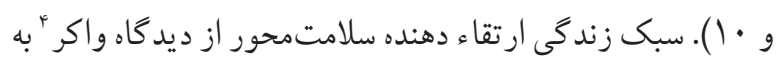
عنوان الكوى جندبعدى از ادراكات و اعمال خودانكيخته كه به تداوم

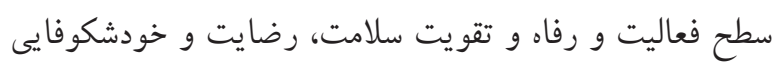

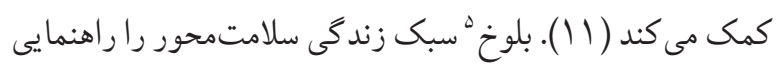

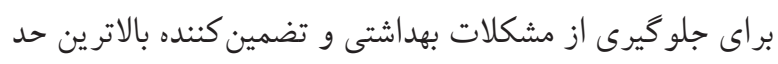

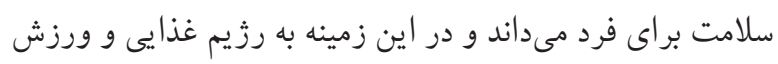

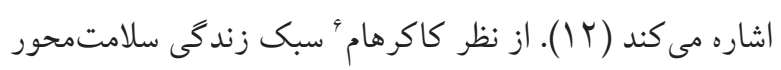

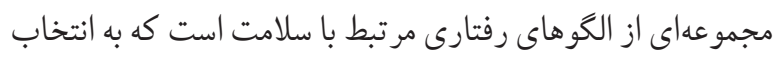

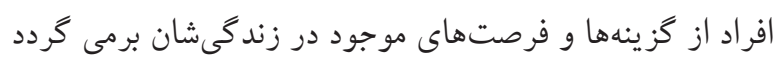

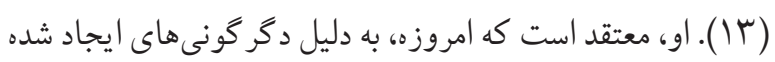

3. healthy life style

4. Walker

5. Belokh

6. Cockerham
نوجوانى دوره تغييرات اساسى نظير تغيير در هورمونها، بدن، محيط

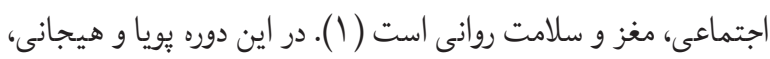
تغييرات جسمى، شناختى، اجتماعى، عاطفى، محيطى اتفاق مى

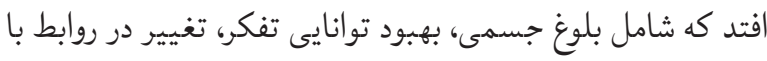

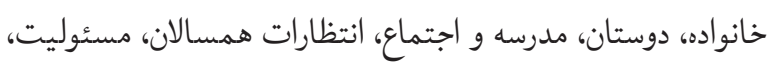
مديريت تكاليف زندگى بدون وابستخى بيش از حد به ديكران و ايجاد جهت كيرى براى آينده به عنوان بزركسالان مستقل و مولد بدان

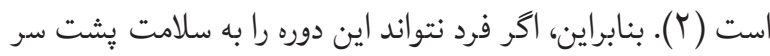

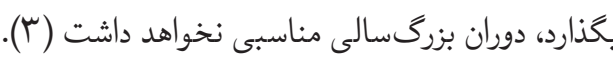

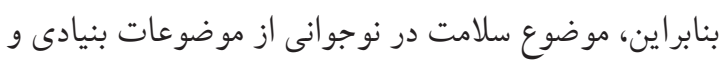

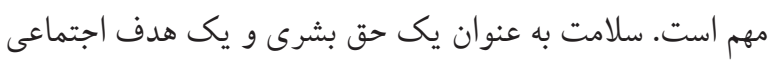
در جهان شناخته شده و براى ارضاى نيازهاى اساسى و بهبود كيفيت زندگى انسان، مهم و حياتى است. متخصصان تعاريف متعددى از

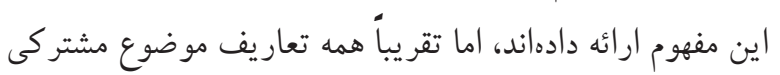

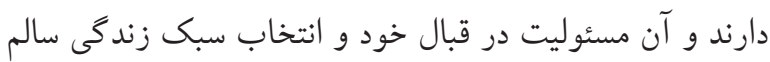

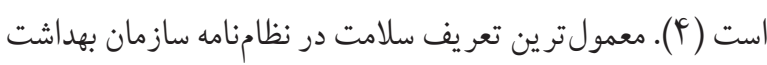

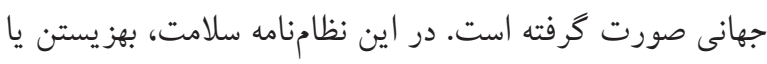
رفاه كامل زيستى، روانى و اجتماعى است و صرف فر فتدان بيمارى

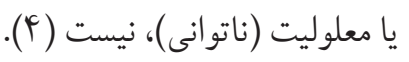

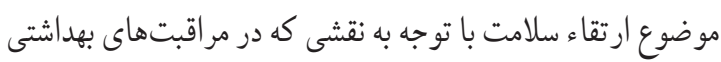
دارد بيوسته مورد توجه سازمان بهداشت جهانى 'بوده است. امروزه

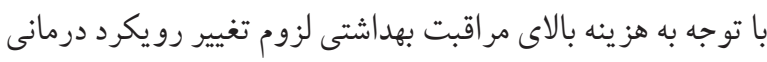

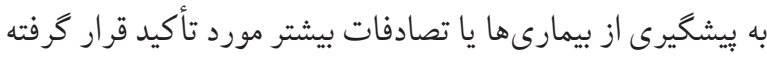

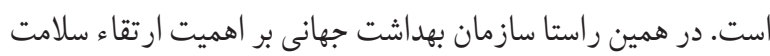
كه شامل تشويق سبك زندگى ' سالم، ايجاد محيط حمايت كننده سلامت، تقويت اقدامات اجتماعى براى بهبود وضعيت سلامت، جهتدهى مجدد خدمات بهداشتى و تعيين سياستهاى بهداشت برات

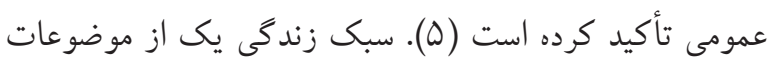

1. World Health Organization

2. life style 
هدفمندى، انعطاف يذيرى و قاطعيت)، باورها (سودمندى روابط

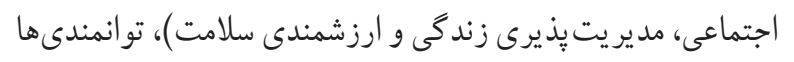

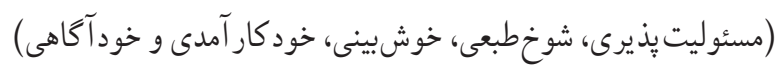
و نكرشها (نكرش نسبت به خود، نكرش نسبت به به رفتارهاى

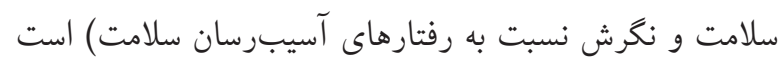

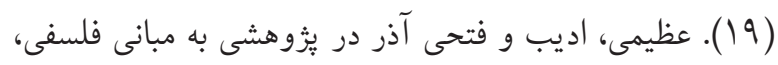

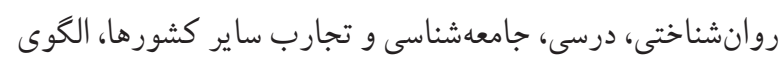

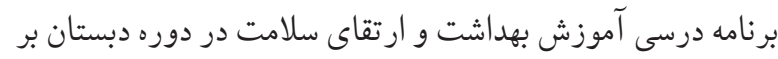

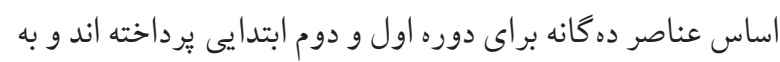
منظور اعتباربخشى الخوى بيشنهادى از نظرات متخصصان تعليم و تربيت و آموزش بهداشت و ارتقاى سلامت استفاده كرده اند. نتايج اعتباريابى نشان داده است كه درصد بالايى از نمونه آمارى

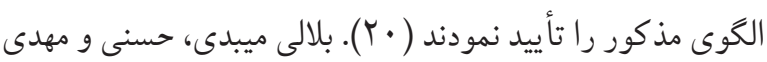
نزاد در يُزوهشى به اين نتيجه رسيدند كه ميانخين نمره سبك ميك

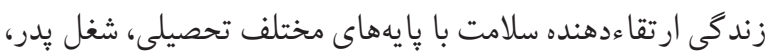

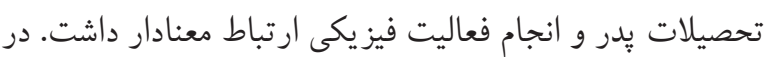

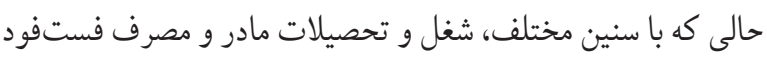

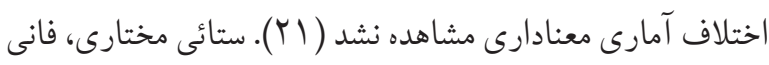

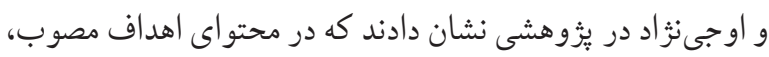

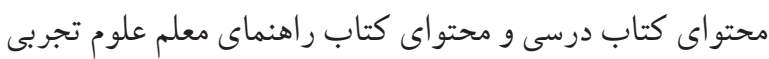

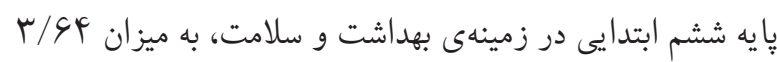

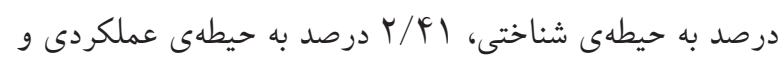

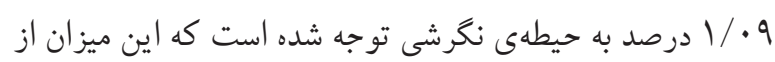

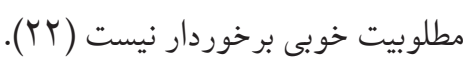

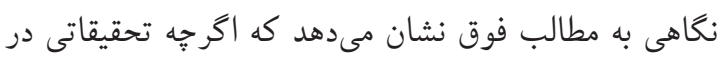

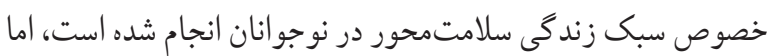

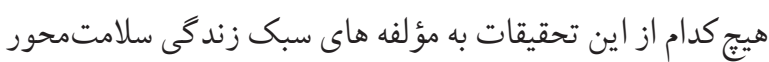

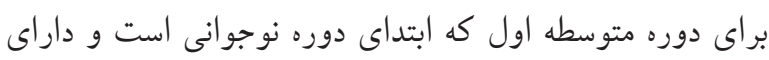

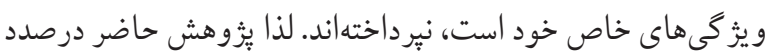

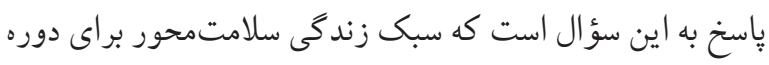

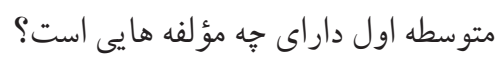

در الخوهاى بيمارى، مدرنيته و هويت اجتماعى، سلامت به عنوان

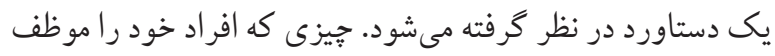

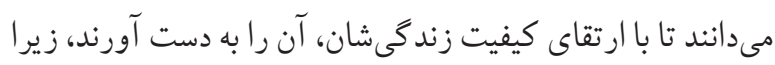

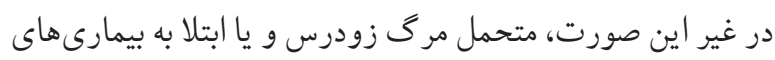

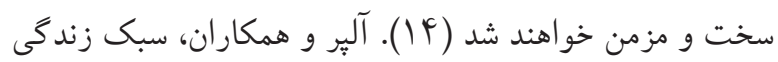
ارتقادهنده سلامت را تركيبى از شش بعد روانى اعتقاد به قدرت برتر خداوند، احساس مسئوليت در قبال حفظ و ارتقاى سلامت

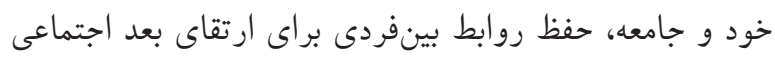

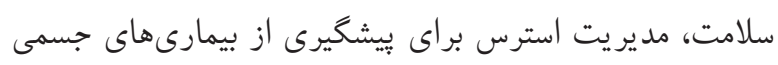

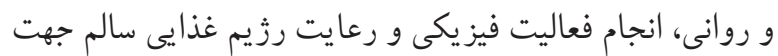
حفظ سلامت در زندكى روزانه مى دانند (ه (1). يُزوهشهاى متعددى در خصوص سبك زند

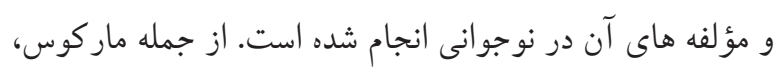

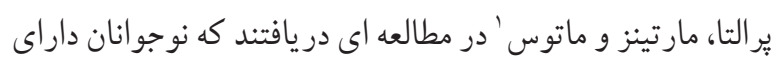

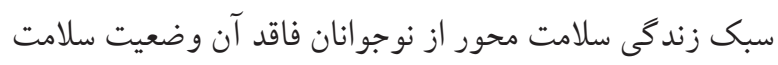

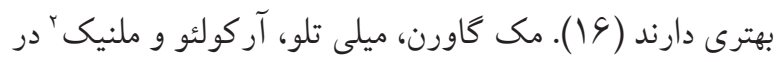

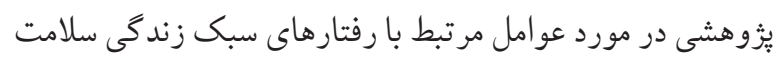

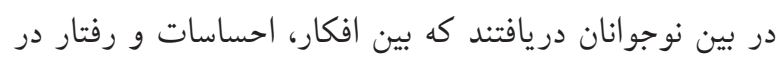
خصوص سبك زندگى سلامت رابطه وجود دارد و در اين مورد

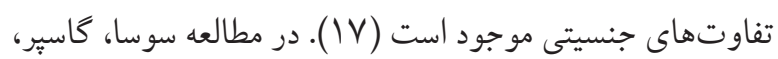
وز، گونزاخا و ديكس بنشان داده شد كه ساختار شش عاملى نيمردخ

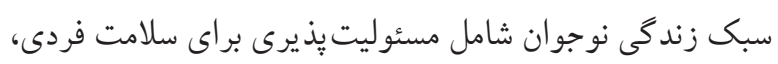

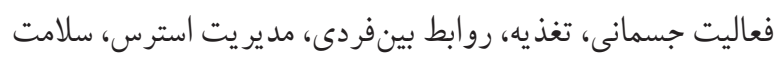
معنوى و جهت گيرى مثبت نسبت به زندگى است (1) (1). همانطور

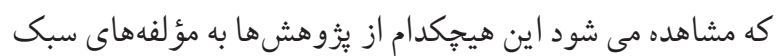
زند گى سلامت - محور نيرداختهاند.

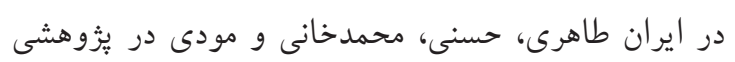

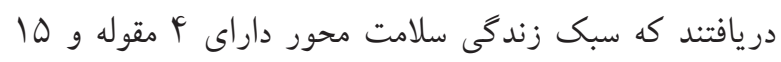
زيرمقوله است كه عبارت از و يز گیى هاى شخصيتى (اراده و پشتكار، 
پِ إز تحليل محتواى مدارك علمى ذكر شده مقوله هاى اصلى، زيرمقوله ها و مفاهيم اوليه مربوط به سبك زندگى سلى سلامت محور

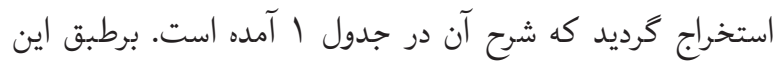

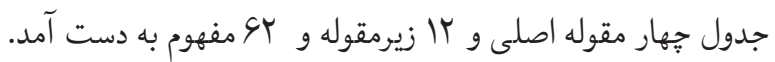
مقوله اصلى اول، سلامت جسمى شامل زيرمقوله هاى تحرك، تغذيه،

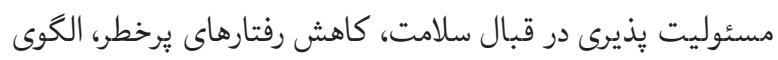

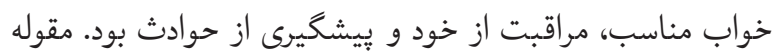

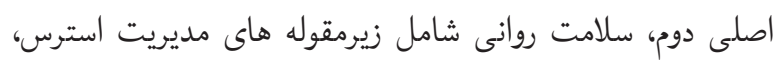
خودشكوفايى و مثبت انديشى و ذهن آكاهى بود. مقوله اصلى سوم

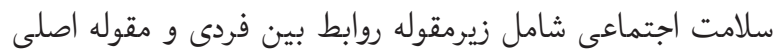

جهارم، سلامت معنوى شامل زيرمقوله رشد معنوى بود.

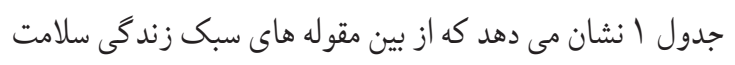

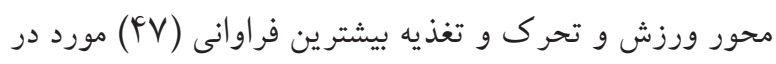

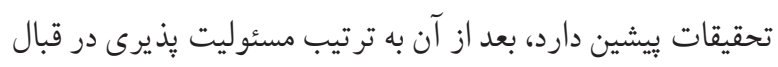

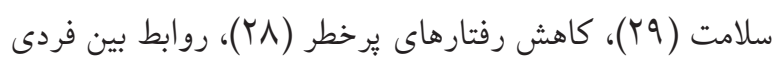

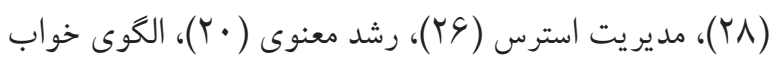

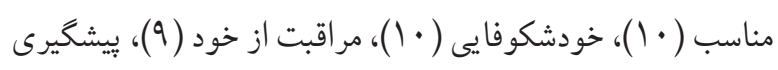
از حوادث (V) و مثبت انديش و ذهن آكاهى (U) قرار مئ كيرند.

\section{بحث و نتيجه كيرى}

بر اساس يافته هاى يزوهش حاضر براى سبك زندگى سلامت محور

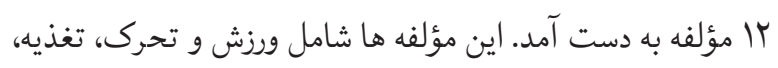
مسئوليت يذيرى در قبال سلامت، كاهش رفتارهاى يرخطر، روابط

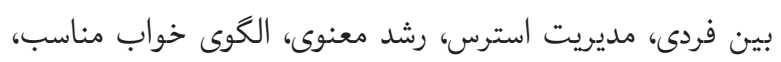

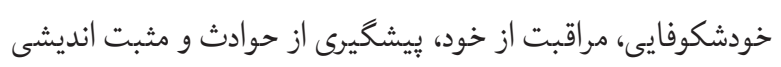
و ذهن آكاهى بودند. ورزش و تحرك در بسيارى از تحقيقات از جمله مهدى زاده

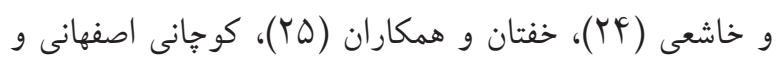

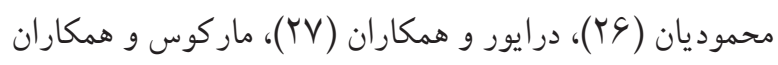

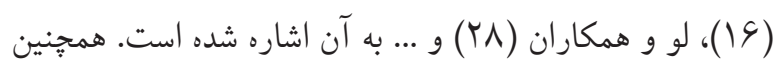

ين يُزوهش با رويكرد كيفى و روش تحليل محتوا انجام شد. بدين

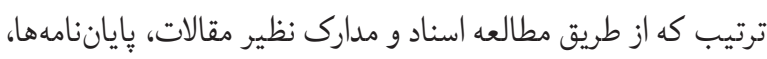
كتابها و ... مؤلفههاى سبك زندكى سلامت محور استخراج شدند.

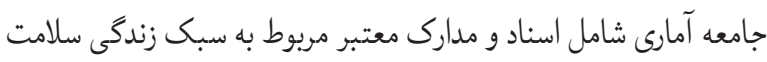

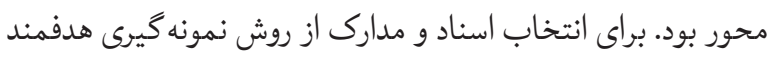

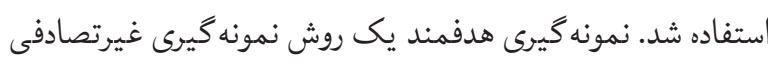

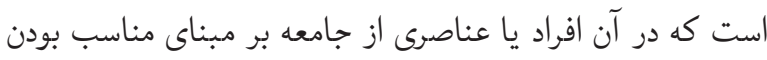

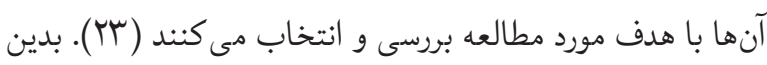

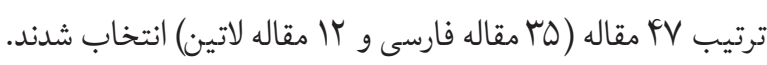
روش انجام يزوهش بدين ترتيب بود كه مقالات فارسى

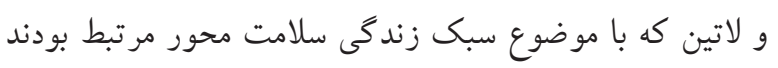

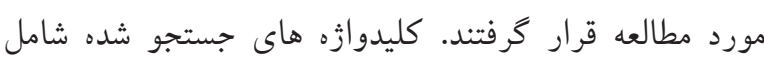
سبك زندگى سلامت محور و سبك زندگى ارتقا دهنده سلامت

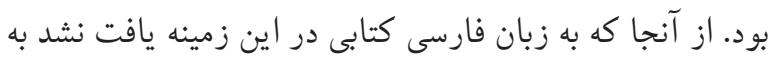

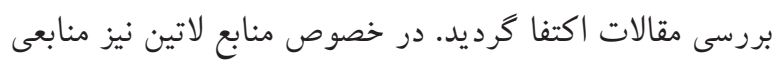

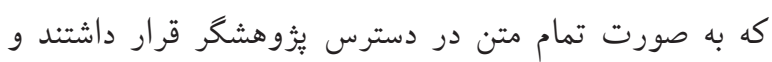

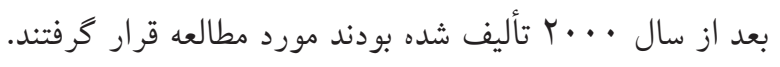

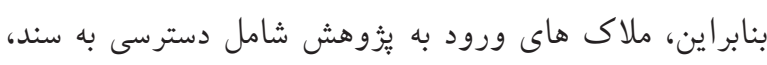

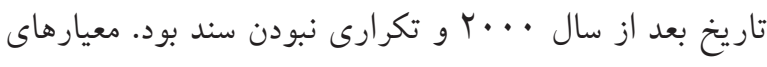

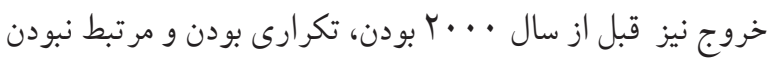
با موضوع بود. يس از مطالعه متن، ابتدا مفاهيم اوليه استخراج

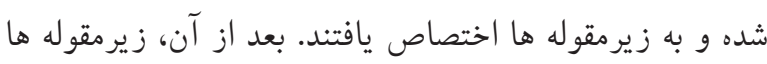

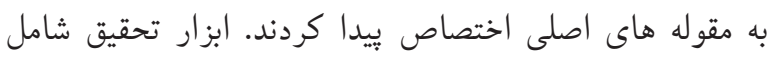

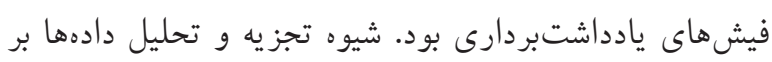
اساس تحليل محتواى كيفى از نوع قراردادى (استقرائى) بود.

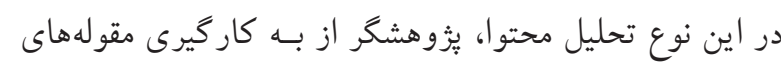

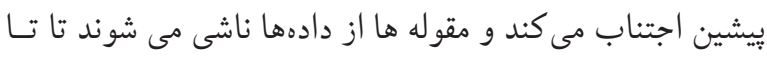

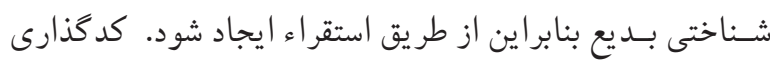

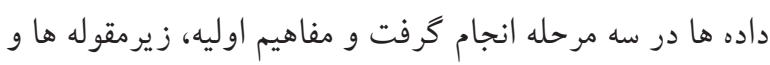
مقوله هاى اصلى به دست آمد. 
$\wedge \Delta$
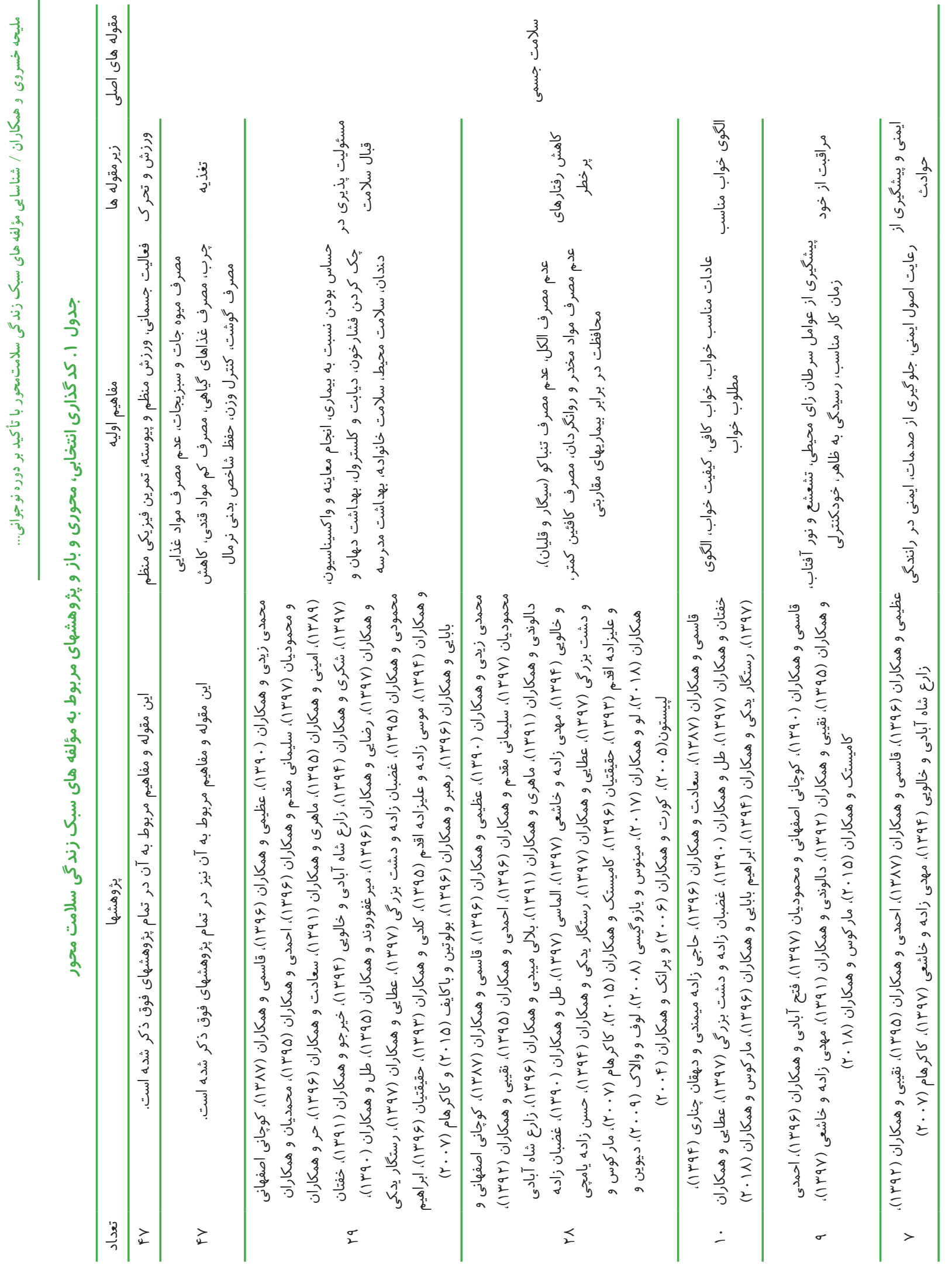


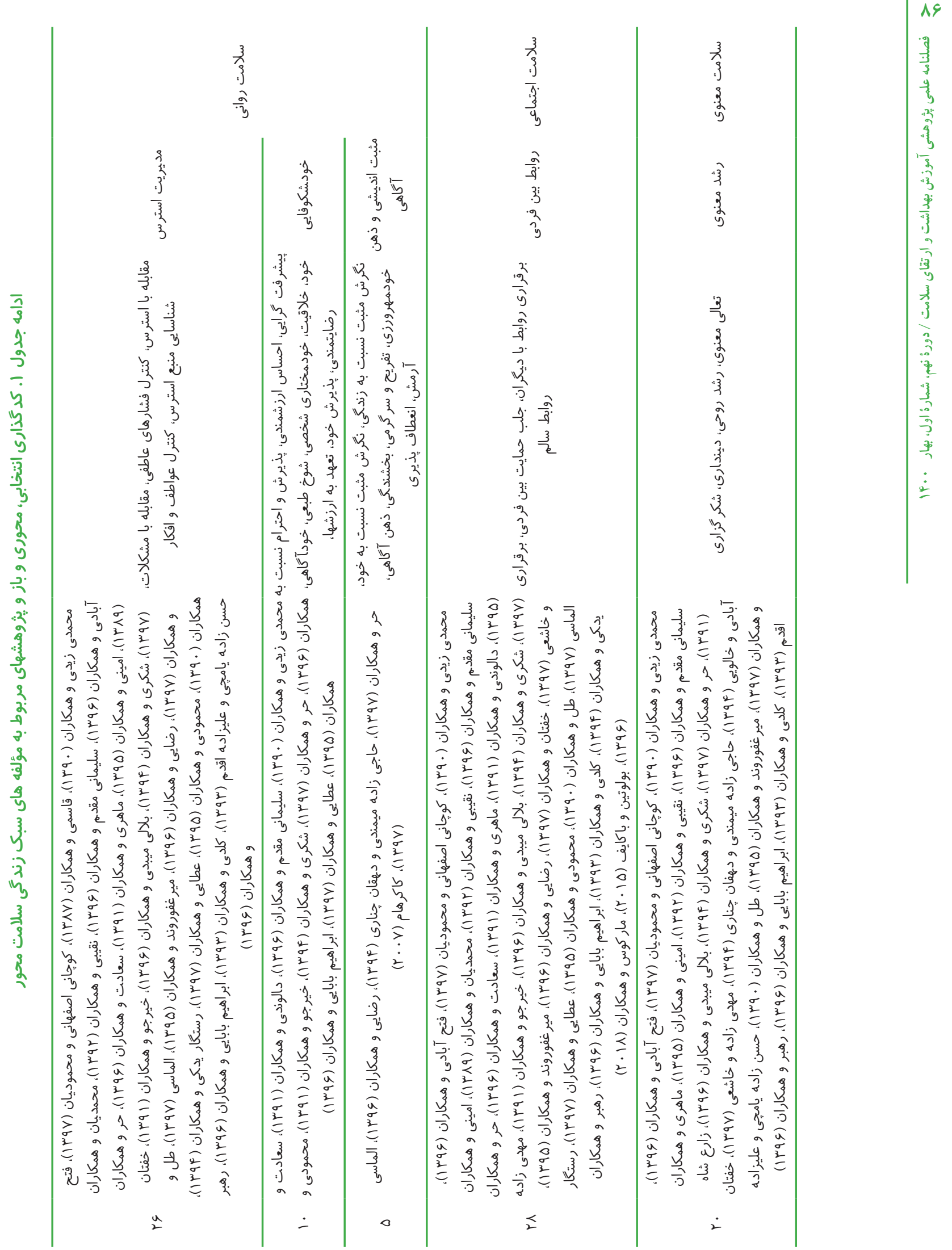




(1)

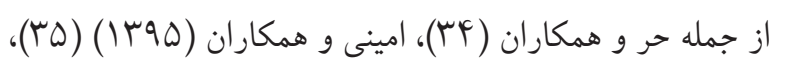
كوجانى اصفهانى و محموديان (Y4)، سليمانى مقدم و همكاران

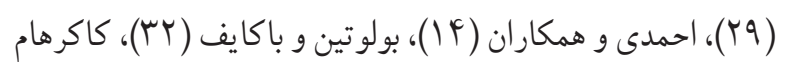

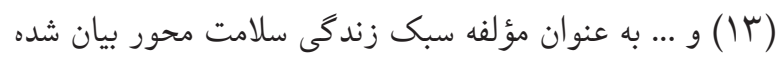

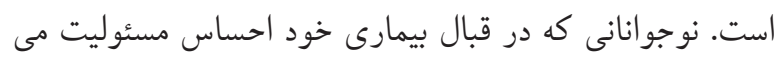

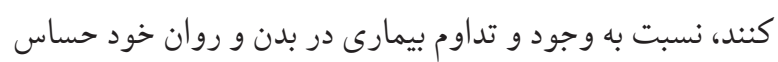
هستند و به محض مشاهده نشانه ها براى رفع آن اقدام مى نما يند.

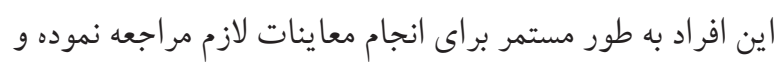

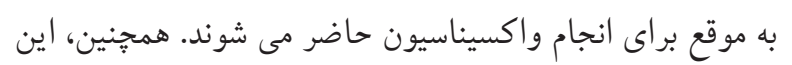

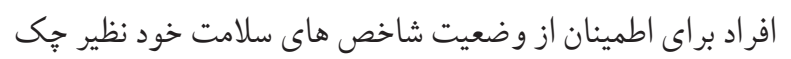
كردن فشارخون، قند خون و كلسترول به مراكز درمانى مراجعه إنه

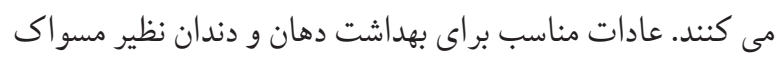
زدن را انجام مى دهند. و در نهايت به سلامت محيط خود اهميت بهادي

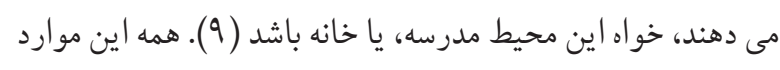

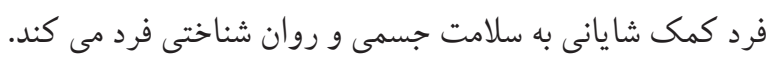
جهارمين مؤلفه سبك زندگى سلامت محور كاهش رفتارهاى

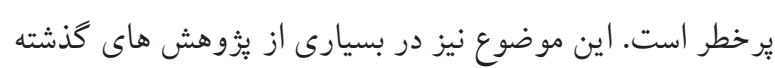

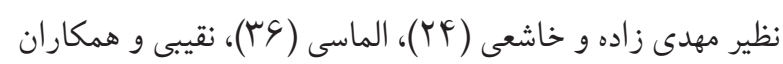

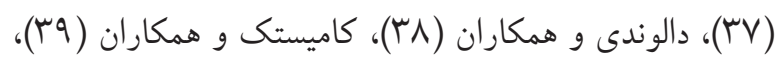

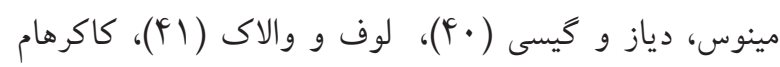

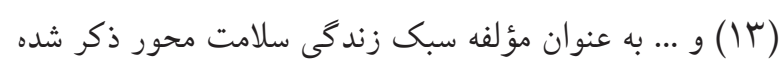

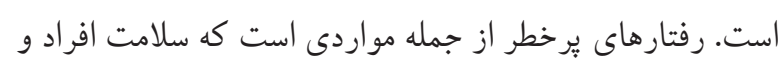

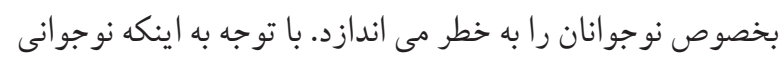

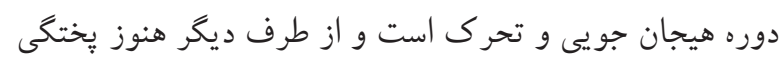
شناختى و خود كنترلى به ميزان كافى رشد نكرده است، احتمال

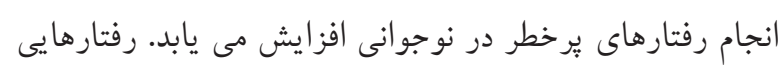
نظير مصرف الكل، مصرف تنباكو (به شكل سيكار، قليان و ... )، مصرف مواد مخدر و روانكردان و حتى مصرف كافئين زياد و نيز

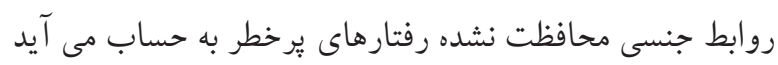

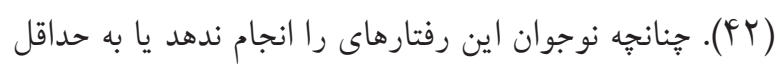
برساند، سلامت او بهبود خواهد يافت.
در مدل سبك زندگى ارتقا دهنده سلامت يندر نيز به عنوان يكى

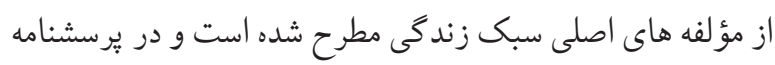
واكر و همكاران كه بر اساس اين نظر يه تهيه شده است به عنو أنوان

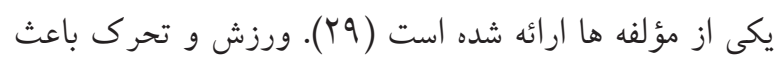

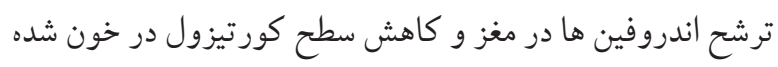

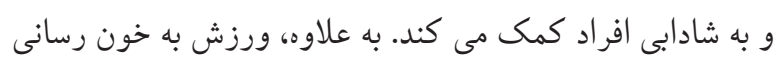

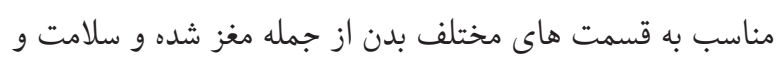

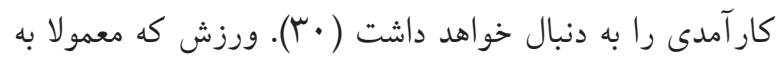

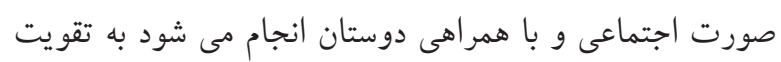

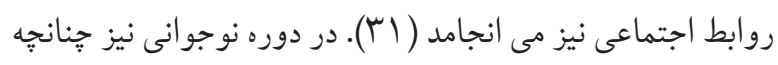

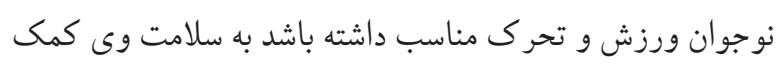
شايانى خواهد كرد.

دومين مؤلفه سبك زندگى سلامت محور، تغذيه است. تغديه

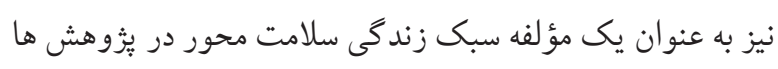

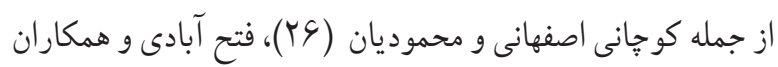

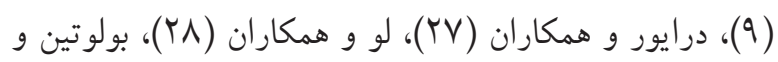

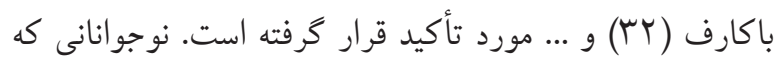
در وعده هاى غذايى از ميوه جات و سبزيجات استفاده مى كنند به رسيدن ويتامين ها و مواد معدنى به بدن خود كمك مى مي كنند.

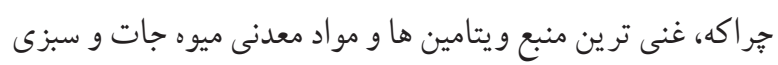

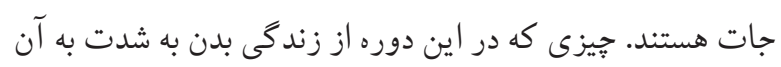

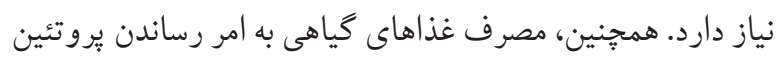
به بدن كمك مى كند دستگاه هاى مختلف بدن از از جمله دستخاه

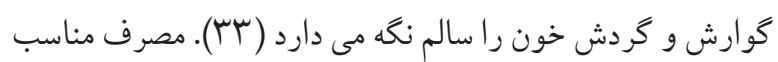

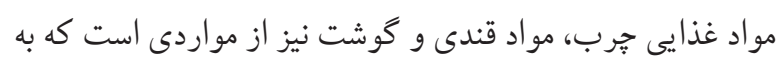

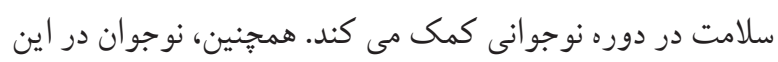

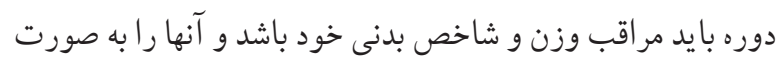

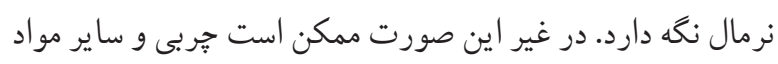

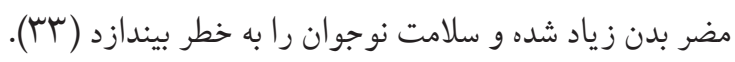

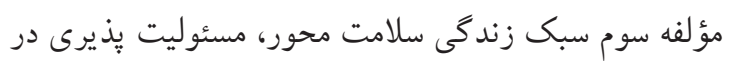
خصوص سلامت است. اين موضوع نيز در بسيارى از يزوهشها 
روانى مبتلا خو اهد شد.

هفتمين مؤلفه سبك زندگى سلامت محور، رشد معنوى است.

در اين خصوص نيز يُزوهش هاى بسيارى رشد معنوى را يكى از

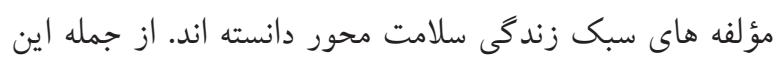

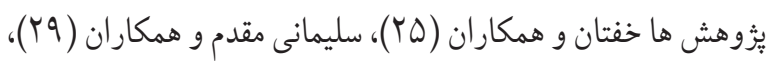

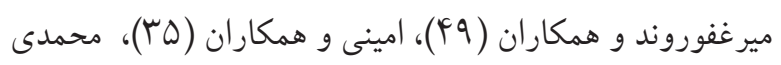
زيدى و همكاران (D) و ... است. يكى از جنبه هاى مهم روانى انسان

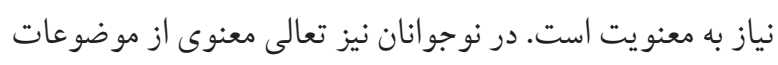

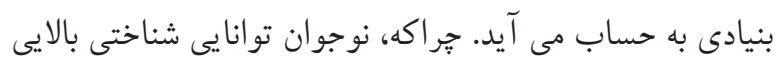

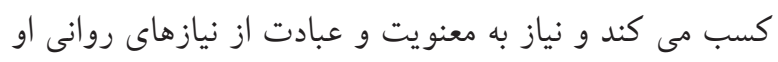
مى كردد. رشد روحى و بهبود روحيه نيز از ويث كيهاى ديكر دوران

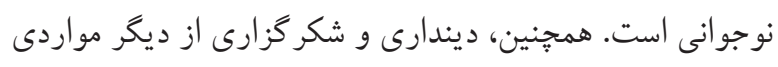

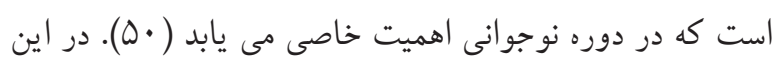

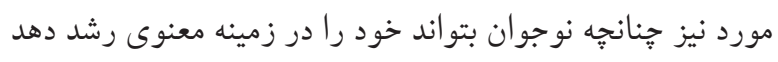
به سلامت روانى وى كمك خواهد شد و در غير اين صورت ممكن است به انحراف كشيده شود. مسئولين از جمله معلمان و مسئولان مدارس بايد زمينه يرورش معنويت در نوجوانان را فراهم نما نمايند.

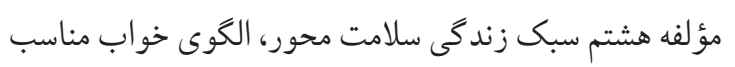
است. يُزوهش هاى كذشته نظير خفتان و همكاران (YO)، غضبان

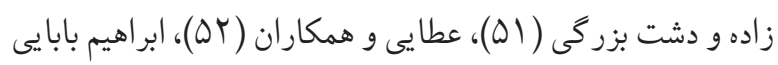

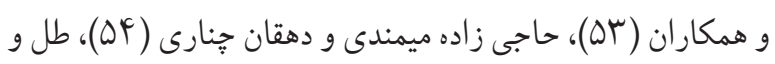

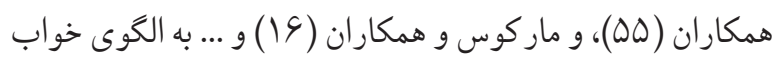

به عنوان يك مؤلفه سبك زندگى سلامت محور اشاره كرده اند.

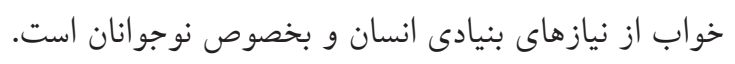

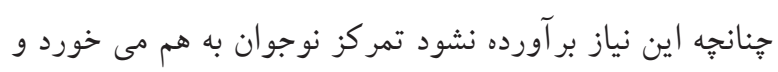

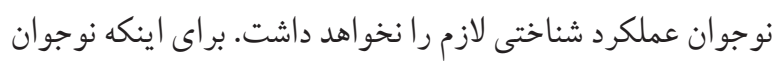
خواب مناسب داشته باشد بايد نوجوان خواب كافى داشته باشد. علاوه راه

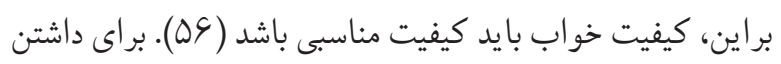

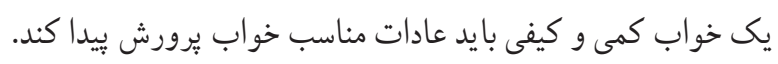

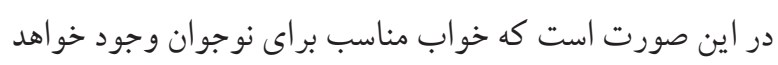
داشت و اين امر به سلامت جسمى و روانى وى كمك خو اهد كر كرد.
مؤلفه پُنجم سبك زندگى سلامت محور، روابط بين فردى

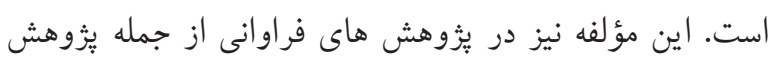

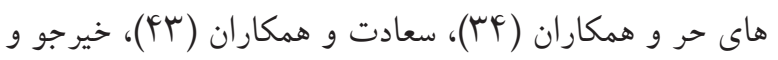

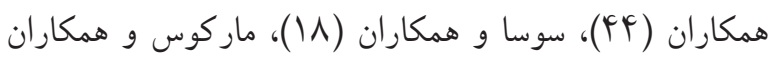

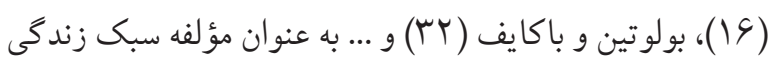
سلامت محور در نظر گرفته شده است. برقرارى روابط با ديخران

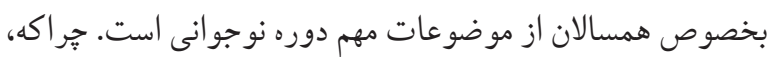

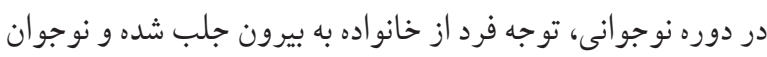

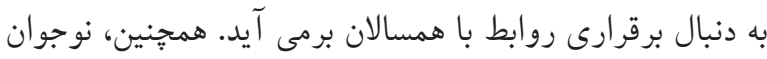

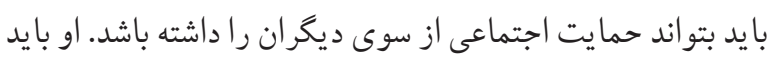

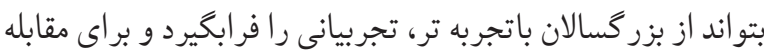

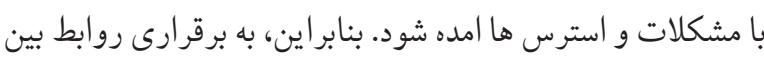

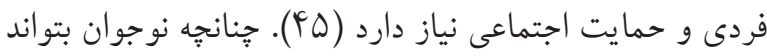

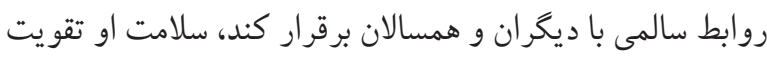

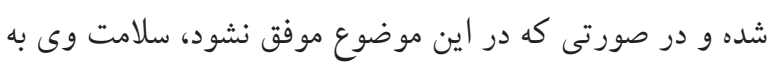

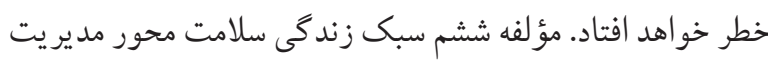

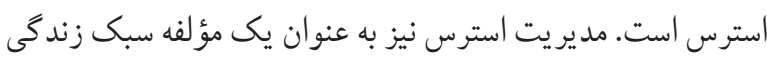
سلامت محور در يُزوهش هايى نظير كو جانى اصفهانى و محموديان

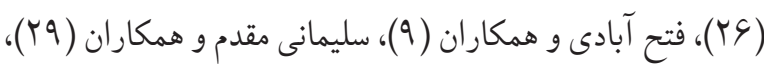

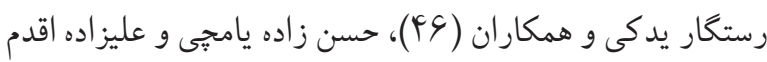
ذكر شده است. از آنجا كه نوجو انى به نظر بسيارى از روان (FV)

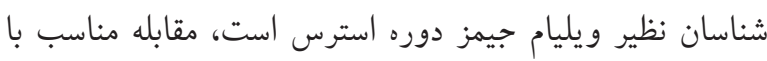

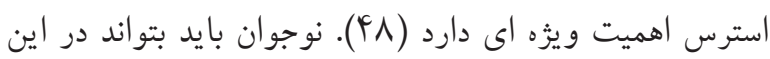

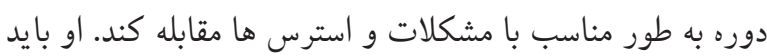

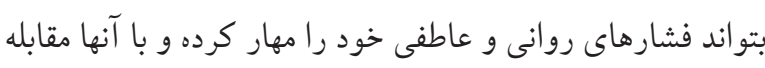

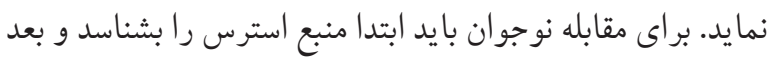

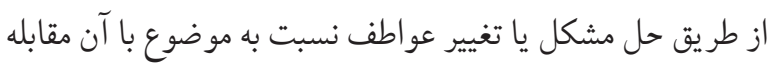

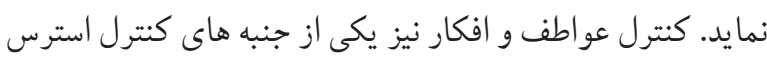

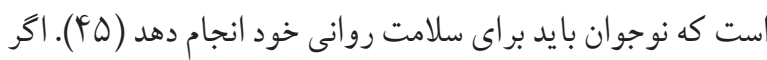
نوجوان در مقابله با استرس موفق باشد سلامت و بخصوص سلد سلامت سلان

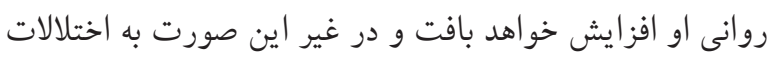


اهميت ويزه اى مى يابد و نوجو انان وقت زيادى را براى رسيدگى

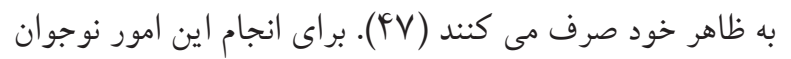

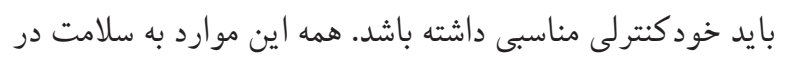
دوره نوجوانى كمك مى كند.

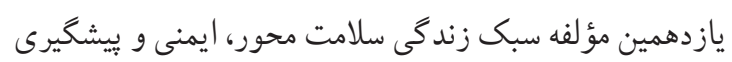

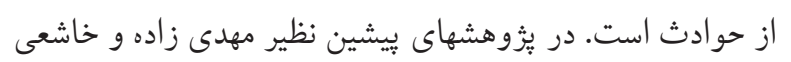

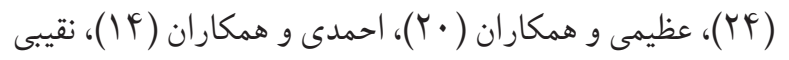

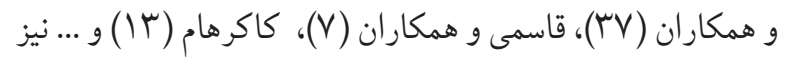

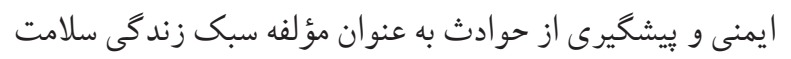

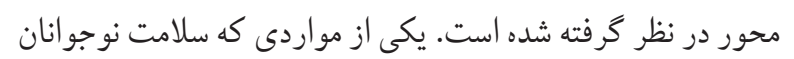

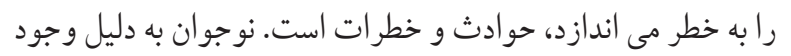

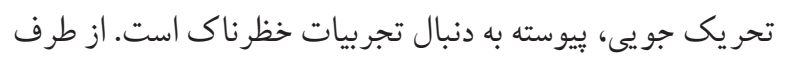

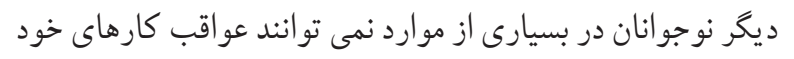

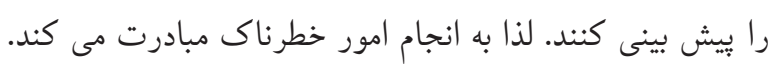
لذا رعايت اصول ايمنى بايد در سرلوحه كار نوجوانان قرار بكيرد.

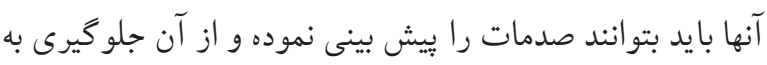

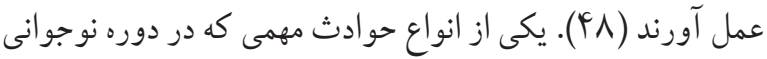

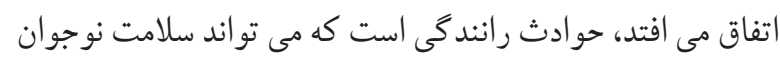

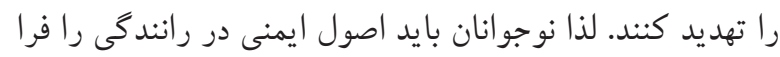
كرفته و رعايت نمايند.

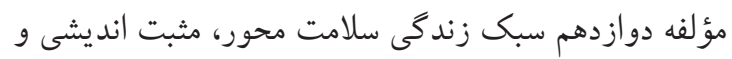

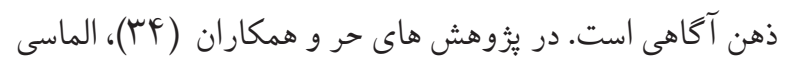

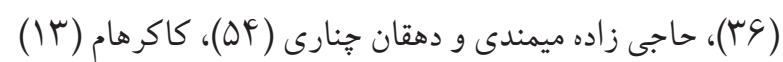

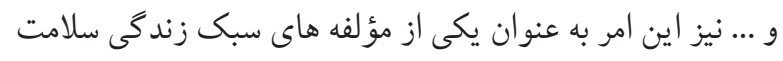

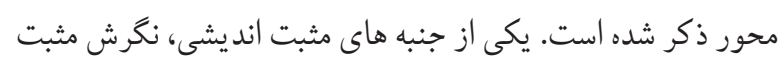

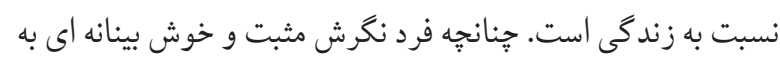

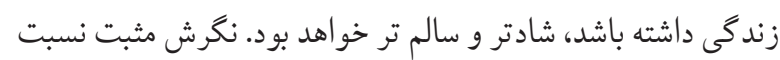

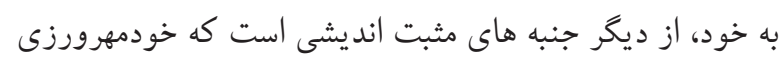

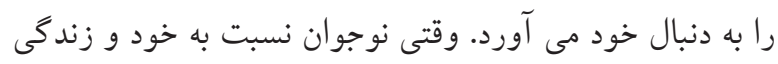

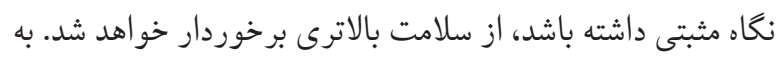

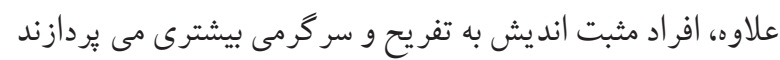

مؤلفه نهم سبك زندگى سلامت محور، خودشكوفايى است. خودشكوفايى نيز در يُزوهش هاى مختلفى از جمله عطايى و همكاران

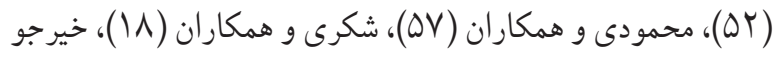

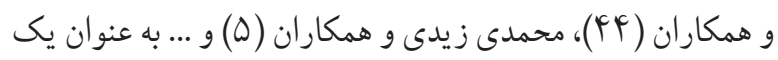

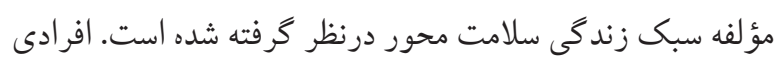

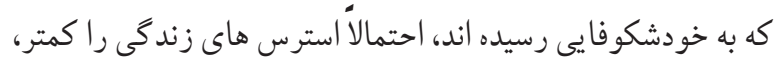
تجربه كرده و ساز كارى بيشترى با شر ايطشان دارند و فعالانه هدايت

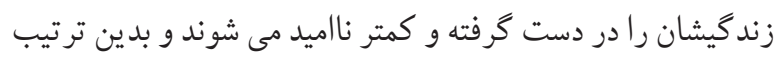

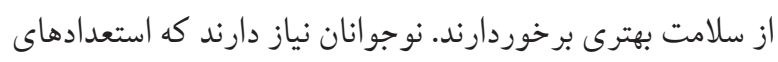

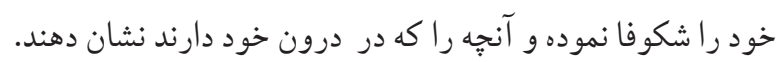
افراد خودشكوفا معمولا، ييشرفت كرا هستند. آنها خود را با تمام

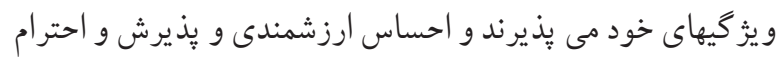

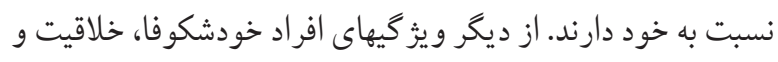

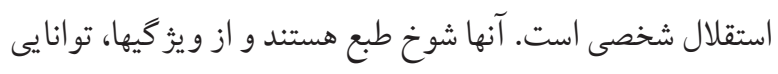

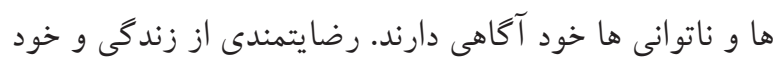

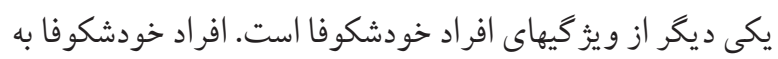

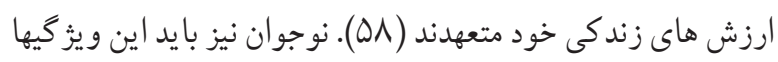
و ويز كيهاى ديخرى را بايد كسب كند تا به خودشكوفايى برسد. مؤلفه دهم سبك زندگى سلامت محور، مر اقبت از خود است.

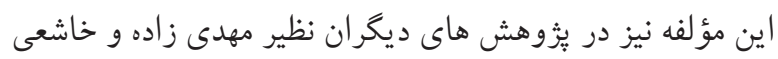

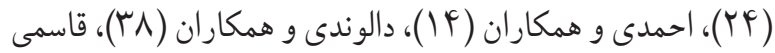

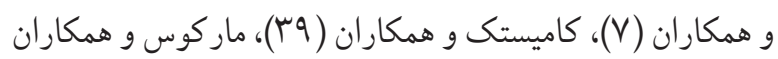

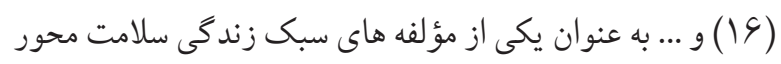
معرفى شده است. نوجوان براى كسب سلامت بايد مر اقب خود باشد. در غير اين صورت ممكن است عوامل آسيب رسان با او صدمه بزنند

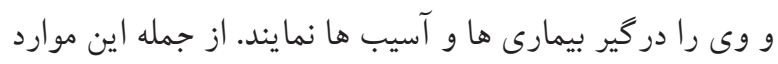

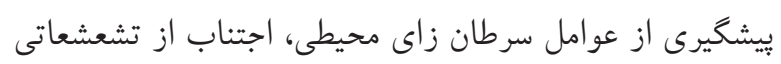

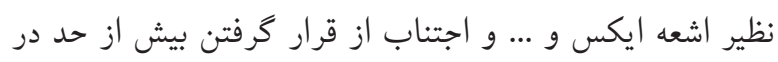

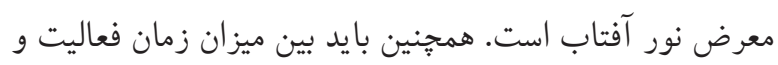
استر احت نوجوان تناسب وجود داشته باشد ( 9). رسيدكى به ظاهر ميز

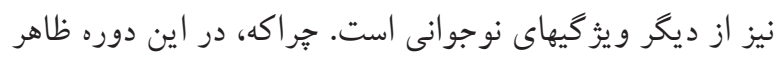


برداشت ها از متون، مشكلاتى در دسترسى به منابع جديد لاتين و

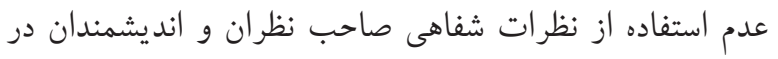

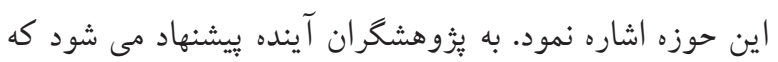

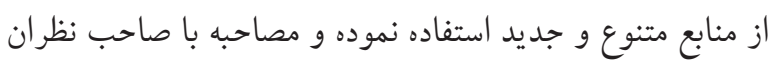

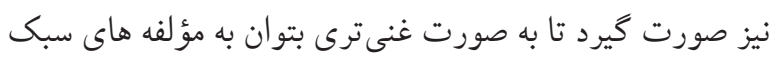

زندگى سلامت محور دست يافت.

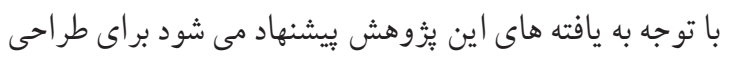

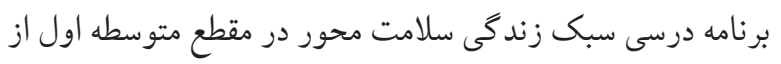

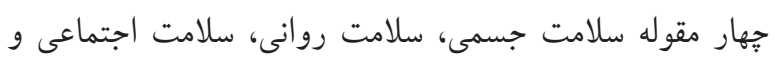

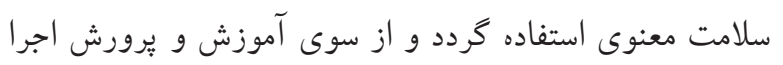

$$
\text { شود تا زمينه سلامت دانش آموزان فر اهم كردد. }
$$

\section{References}

1. Blakemore $\mathrm{S}$ J. Adolescence and mental health. Lancet, 2019; 393: 2030-1. https://doi.org/10.1016/S0140-6736(19)31013-X

2. Vahedian-Shahroodi $M$, Tehrani $H$, Robat-Sarpooshi D, GHolian-Aval M, Jafari A, Alizadeh-Siuki $H$. The impact of health education on nutritional behaviors in female students:Anapplicationofhealthbeliefmodel.International Journal of Health Promotion and Education. 2019:1-13. https://doi.org/10.1080/14635240.2019.1696219

3. Brownell KD, Schwartz MB, Puhl RM, Henderson KE, \& Harris JL. The need for bold action to prevent adolescent obesity. JAdol Heal, 2009; 45(3 Suppl): 8-17. https://doi.org/10.1016/j.jadohealth.2009.03.004 PMid:19699441

4. Yazdi Feyzabadi V, Seyfaddini R, GHandi M, Mehrolhasani $M$. The World Health Organization's Definition of Health: A Short Review of Critiques and Necessity of A Shifting Paradigm. irje. 2018; 13:155-165. [in Persian].

5. Mohammadi Zeidi I, Pakpour Hajiagha A, Mohammadi Zeidi B. Reliability and Validity of Persian Version of the HealthPromoting Lifestyle Profile. J Mazandaran Univ Med Sci. 2012; 21 (1):102-113.

6. Naghizadeh S, Ebrahimpour maleki M, Patras G, Jafari M. Comparison of Health Promoting Lifestyle and Self-Efficacy in Female Students with and Without Primary Dysmenorrhea. Iranian Journal of Health Education and Health Promotion. 2019;7(3):285-94.
و تجربه هاى مثبت بيشترى را تجربه مى كنند. انعطاف يذيرى نيز از ديخر ويثزيهاى افر اد مثبت انديش است (م9). لذا نوجوان با كسب اين ويز گيها مى تواند مثبت انديشى را كسب نموده و سلامت خود را بهبود بخشد.

به طور كلى مى توان دوازده مؤلفه سبك زندگى سلامت محور را در جهار مقوله اصلى سلامت جاى داد: سلامت جسمى (تحرك، تغذيه، الخوى خواب مناسب، كاهش رفتارهاى ڤبرخطر، مسئوليت ڤذيرى در قبال سلامت، ييشخيرى از حوادث و مراقبت از خود)، سلامت روانى (مديريت استرس، خودشكوفايى، مثبت انديش و ذهن آكاهى)، سلامت اجتماعى (روابط بين فردى) و سلامت معنوى (رشد معنوى). از محدوديتهاى اين يثوهش مى توان به تفاوت احتمالى در

https://doi.org/10.29252/ijhehp.7.3.285

7. Ghasemi V, Rabani Khorasgani R, Rabani Khorasgani A, Alizade Aghdam MB. Structural and capital determinants of helthy lifestyle. Literature and Humanistics Faculty Journal (Kharazmi uniwersity), 2008; 16(63): 181-213.

8. Neymotin F. \& Nemzer LR. Locus of control and obesity. Frontiers in Endocrinal, 2014; 159: 1-4. https://doi.org/10.3389/fendo.2014.00159 PMid:25339940 PMCid:PMC4188137

9. Fathabadi J, Sadeghi S, Jomhari F, Talaneshan A. The role of health-oriented lifestyle and health locus of control in predicting the risk of overweight. Iranian Journal of Health Education and Health Promotion. 2017;5(4):280-7. https://doi.org/10.30699/acadpub.ijhehp.5.4.280

10. Kumar S, Preetha GS. Health promotion: An effective tool for global health. Indian Journal of Community Medicine, 2012; 37 (1): 1-5. https://doi.org/10.4103/0970-0218.53377 https://doi.org/10.4103/0970-0218.62543 https://doi.org/10.4103/0970-0218.39233 https://doi.org/10.4103/0970-0218.170955 https://doi.org/10.4103/0970-0218.94009 https://doi.org/10.4103/0970-0218.45367 PMid:19876446 PMCid:PMC2763655

11. Walker SN. A Spanish language version of the health-promoting life-style profile. Nurse Research, 1990; 39(5): 268-273. https://doi.org/10.1097/00006199-199009000-00003 
12. Eshghizadeh M, Delshad noughabi A, Akbari S, Majidi F, Khalili F. Relationship between health literacy and lifestyle in patients at risk and with chronic obstructive pulmonary disease. Journal of Health Literacy. 2020;5(1):61-8.

13. Cockerham WC. Health life styles and the absence of the Russian middle class. Sociology of Health and Illness, 2007; 29(3): 457-473. https://doi.org/10.1111/j.1467-9566.2007.00492.x PMid:17470221

14. Ahmadi Y, Mohamadzade H, Aliramaie S. Relationship between Types of Capital and Healthy Lifestyle in Sanandaj Women . refahj. 2016; 16 (61):107-139.

15. Alpar SE, Senturan L, Karabacak U, Sabuncu, N. Change in the health promoting lifestyle behaviour of Turkish University nursing students from beginning to end of nurse training. Nurse Education in Practice, 2008; 8(6): 382-388. https://doi.org/10.1016/j.nepr.2008.03.010 PMid:18495538

16. Marques A, Peraltaa M, Santos T, Martinse J, Gaspar de Matos M. Self-rated health and healthrelated quality of life are related with adolescents' healthy lifestyle. Public Health, 2019; 170: 89-94. https://doi.org/10.1016/j.puhe.2019.02.022 PMid:30978580

17. McGovern CM, Militello LK, Arcoleo KJ, Melnyk BM. Factors associated with Healthy Lifestyle Behaviors among adolescents. Journal of Pediatric Health Care, 2018; 32(5): 473-480. https://doi.org/10.1016/j.pedhc.2018.04.002 PMid:29941235 PMCid:PMC7265997

18. Sousa P, Gaspar P, Vaz DC, Gonzaga S. \& Dixe A. Measuring Health-Promoting Behaviors: Cross-Cultural Validation of the Health-Promoting Lifestyle Profile-II. International Journal of Nursing Knowledge, 2015; 26 (2): 54-61. https://doi.org/10.1111/2047-3095.12065 PMid:25389054

19. Taheri M, Hassani J, Mohammadkhani S, Moudi M. Explanation psychological components of Healthy lifestyle: A qualitative study. J Health Syst Res, 2017; 13(4): 491-6.

20. Azimi M, Adib Y, Fathi Azar E. Designing and validation of curriculum health instruction and health promotion in primary schools based on health system assumptions. Doctoral thesis of university of Tabriz, 2016.

21. Balali Meybodi F, Hasani M, Mehdinejad M. Evaluating Health-promoting Life Style and Its Related Factors among Adolescent Girls of Kerman in 2015. Health Develop J. 2017; 6 (2):85-96.

22. Setayi Mokhtari R, Fani H, Owjonejad AR. Study of pay attention to health components in curriculum of experimental sciences of sixth grade of primary school. MA thesis of Islamic Azad university, Marvdasht branch. 2014.

23. Bayani AA. Methodology: quantity, Quality and mixed. Azadshar: Islamic Azad University Press; 2015.

24. Mehdizade SM, Khashei R. Role of media on selecting healthy lifestyles (emphasized on media use of tehranian). Quarterly Journal of Communication Research, 2018; 25(2): 51-78.

25. Kheftan P, Gholami Jam F, Amirpour B, Arshi M, Eghlima M, Rahgozar M. pilepsy -Related Stigma Based on Health -Related Life Style Components. Iranian Journal of Nursing Research (IJNR), 2018; 13(4): 72-78.

26. Koochani Isfahani M, Mahmoodian H. Study of effect of cultural capital on general health with mediating healthy lifestyle (Case study: high school students of Shiraz city). Applying sociology (Research Journal of Human Sciences of Isfahan University), 2018; 29(2): 1-16.

27. Driver S, Juengst $S$, McShanab EE, Bennett $M$, Bellac K, Dubiel R. A randomized controlled trial protocol for people with traumatic brain injury enrolled in a healthy lifestyle program (GLB-TBI). Contemporary Clinical Trials Communications, 2019; 14: 1-9. https://doi.org/10.1016/j.conctc.2019.100328 PMid:30775611 PMCid:PMC6365803

28. Lv J, Yu C, Guo Y, Bian Z, Yang L, Chen Y, XuefengTang P, Zhang W, Qian Y, Huang Y, Wang X, Chen J, Chen Z, LuQi P, Li L. Adherence to Healthy Lifestyle and Cardiovascular Diseases In the Chinese Population. Journal of the American College of Cardiology, 2017; 69(9): 1116-1125. https://doi.org/10.1016/j.jacc.2016.11.076 PMid:28254173 PMCid:PMC6675601

29. Soleimani Moghadam R, Mohammadi S, Kargar Kakhki N, Mohammadi M, Ghadimifar A, Ahmadnejad A, Talaei Bagestani, A, Nemat Allahi WR, Mohammadzadeh AR, Ghayour Mobarhan M, Mohammadzadeh F. Evaluation the predictors in patients with cardiovascular disease based on Walker health-promoting lifestyle. Iranian Journal of Diabetes and Metabolism, 2018; 17(3): 157-64.

30. Yaghoobi H, Baradaran M. Codependence of mental health: Happiness, exercise and emotional intelligence. New Research of Psychology (Psychology of Tabriz University), 2011; 6(23): 201-221.

31. Laker A. The sociology of sport and physical education (1st Ed.). London: Routledge Flamer Press; 2002.

32. Bolotin A, Bakarev V. Structure and content of the educational technology of managing students' healthy 
lifestyle. Journal of Physical Education and Sport, 2015; 15(3): 362 - 364.

33. Akhlaghi M, Babajafari S, Razmjouee N, Bagheri $\mathrm{S}$. Association Between Dietary Indices and Eating Habits in 20-50 Years Adults in Shiraz . Iranian Journal of Nutrition Sciences \& Food Technology. 2018; 13 (1):11-20.

34. Hor M, Aghaei A, Abedi A, Golparvar M. Effect of Combined Treatment Package (ACT-based healthy lifestyle) with Mindfulness-based Therapy on Self-care and Glycated hemoglobinin Patients with Diabetes Mellitus, Type2. Islamic LifeStyle Centeredon Health, 2018; 2(2): 63-68.

35. Amini R, Rajabi M, Omidi A, Soltanian AR, Esmaeili M. Effect of selfe-management of healthy lifestyle on health promotion bebaviors of Ischemic patient: a clinical study. Nursing and Midwifery Journal of Hamedan (Nasim Danesh), 2016; 24(3): 174-183. https://doi.org/10.21859/nmj-24035

36. Almasi M. Determinants of the Elderly's Healthy Lifestyle in Ilam. IJN. 2018; 31 (111):75-85. https://doi.org/10.29252/ijn.31.111.75

37. Naghibi F, Golmakani N, esmaeili H, Moharari F. Study of relationship between lifestyle relared to health aming female high school adolescents of Mashad city. IJOGI, 2013; 16(61): 9-19.

38. Dalvandi A, Seyed Bagher Maddah S, Khankeh HR, Bahrami F, Parvaneh Sh, Hesam Zadeh A, et al. The Health-Oriented Lifestyle in Islamic Culture. J Qual Res Health Sci 2013; 1(4): 332-43.

39. Chomistek AK, Chiuve SE, Eliassen AH, Mukammel KJ, Willett WC, Rimm EB. Healthy lifestyle in the primordial prevention of cardiovascular disease among women. Journal of the American College of Cardiology, 2015; 65(1): 43-51. https://doi.org/10.1016/j.jacc.2014.10.024 PMid:25572509 PMCid:PMC4291551

40. Minous AG, Diaz VA, Geesey ME. Acculturation and healthy life style among Latinos with diabetes. Annals of Family Medicine, 2008; 6(2): 131-137. h tt ps: / / d o i . org / $10.1370 /$ a f m .814 PMid:18332405 PMCid:PMC2267424

41. Loef $M$, Walach $H$. The combined effects of healthy lifestyle behavior in all cause mortality: A systematic review and metaanalysis. Preventive Medicine, 2012; 55: 163-170. https://doi.org/10.1016/j.ypmed.2012.06.017 PMid:22735042

42. Rashid K. (2015). Risky behaviors among male and female adolescent students of Tehran. Social Welfare quarterly. 2015; 15(75): 31-56.

43. Saadat S, Kalantari M, Kajbaf M. The Relationship between Health-Promoting Lifestyle (HPL) and Academic Self-Efficacy among students. RME. 2017; 9 (4):38-30. https://doi.org/10.29252/rme.9.4.38

44. Kheirjoo E, Jomehri F, Ahadi H, Farshbaf Manisefat F. Comparison of Health Promoting Lifestyle of Female Rheumatoid Arthritis Patients with Healthy Women and It's Relationship with Demographic Factors. Knowledge \& Research in Applied Psychology, 2012; 13(4, Continuous No. 50): 61-70.

45. Rathus SA. Psychology (10th ed.). Fort Worth: Holt, Rinehart and Winston; 2011.

46. Rastegar Yadaki M, Zendetalab HR, Mazloom SR. Yavari M. Effectiveness of peer instruction on health promotion lifestyle among health connectors. Nurse Education, 2017; 6(2 continuous 22): 9-18. https://doi.org/10.21859/jne-06022

47. Hasanzadeh Yamchi, Alizadeh Aghdam MB. Examination of the relationship between lifestyle (health-based) and cultural capital among students of Hadishahr Islamic Azad University. Sociology Studies, 2014; 6(24): 85-98. [in Persian].

48. Berk L. Developmental psychology (2th ed). Tranated by Seidmohamadi Y. Tehran: Arasbabran; 2014.

49. Mirghafourvand $M$, Mohammad-Alizadeh Charandabi S, Behroozi lak T, Aliasghari F.[Assessment of health promoting lifestyle status and its socio-demographic predictors in women with polycystic ovarian syndrome]. Hayat, Journal of School of Nursing and Midwifery, Tehran University of Medical Sciences. 2016; 22(4): 394-407.

50. Movahed M, Karami F. Religion and health: Study of relationship between religion and healthy lifestyle among Shiraz citizens. Sociology of Social Institutions, 2019; 6(13): 127-148.

51. Ghazbanzadeh R, DashtBozorgi A. Predicting Subjective Well-Being Based on Health Promoting Lifestyle, WorkFamily Conflict and Job Satisfaction among Exceptional School Teachers. Journal of Health Promotion Management (JHPM), 2018; 7(5): 14-21.

52. Ataei J, Kamran A, Shekarchi, AA, Etebar I, Haghiri E, Gorbani M. Study of Health Promotion LifeStyle (HPLP) of Rural Primary Health-Care Workers (Behvarzes) in Khalkhal and Kosar Counties. Journal ofHealth, 2019; 9(5): 530-540. https://doi.org/10.29252/j.health.9.5.530

53. Ebrahimbabaie $F$, Habibi M, Ghodrati S. Comparison of Health Promoting Lifestyle in HIVpositive and HIV-negative Individuals in Tehran. J Educ Community Health. 2017; 4 (3):38-43. https://doi.org/10.21859/jech.4.3.38 
54. Hajizade Meimandi M, Dehghan Chenari M. Healthy lifestyle and marital satisfaction among married women of Yazd city. Woman in Culture and Art (Women Research); 7(1): 61-76.

55. Tol A, Tavassoli E, Shariferad GH, Shojaezadeh D. Relation between Health-Promoting Lifestyle and Quality of Life in Undergraduate Students at School of Health, Isfahan University of Medical Sciences, Iran. Journal of Health System research, 2011; 7(4): 442-8.

56. Moore M, Kirchner HL, Drotar D, Johnson N, Rosen C, Ancoli-Israel S, Redline S. Relationships among Sleepiness, Sleep Time, and Psychological Functioning in Adolescents. Journal of Pediatric Psychology, 2009; 34(10):1175-83. https://doi org/10.1093/jpepsy/jsp039 PMid:19494088 PMCid:PMC2782255
57. Mahmoodi H, Asghari Jafarabadi M, Mohammadi $Y$, Shirzadi SH, Doshmangir P, Sharifisaqezi P. Correlation of Body mass index and health-promoting lifestyle among health care workers of Saqqez city. Health Promotion Management, 2016; 5(2): 42-51.

58. Shultz DP, Shultz SE, Personality Theories. Translated dy seidmohammadi Y. Tehran: Virayesh, 2013.

59. Ghahremani L, Kaveh $\mathrm{MH}$, Tehrani H, Orooji A, Jafari A. Assessment of the theory of planned behaviour in predicting potential intention and behaviour of positive thinking among a school-based sample of Iranian adolescents: a path analysis. Journal of Psychologists and Counsellors in Schools.1-11. https://doi.org/10.1017/jgc.2020.13 